\title{
A MEDIAÇÃO COMO FORMA DE RESOLUÇÃO DE CONFLITOS: UMA ABORDAGEM APLICADA DO PENSAMENTO DE HANNAH ARENDT
}

\author{
MEDIATION AS A FORM OF CONFLICT RESOLUTION: AN APPLIED APPROACH TO \\ THE THINKING OF HANNAH ARENDT
}

\section{LA MEDIACIÓN COMO FORMA DE RESOLUCIÓN DE CONFLICTOS: UN ABORDAJE APLICADO DEL PENSAMIENTO DE HANNAH ARENDT}

\section{Jovina d'Avila Bordoni ${ }^{1}$}

\section{Natercia Sampaio Siqueira ${ }^{2}$}

Licença CC BY:

Artigo distribuído sob os termos Creative

Commons, permite uso e distribuição irrestrita em qualquer meio desde que o autor credite a fonte original.

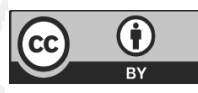

\begin{abstract}
Resumo: O estudo aborda a mediação como instrumento de resolução dos conflitos. Busca-se repensar a relação entre os indivíduos e a forma de solução dos seus conflitos, por meio da mediação, com base nos conceitos e nas discussões de Hannah Arendt sobre política, cidadania e amizade. Ao assim proceder, arguise que a prática dialógica é condição para que se seja pessoa com igual dignidade a qualquer outra, para, em momento posterior, se ponderar que a tecnologia do diálogo, em vez da descoberta da verdade, é a prática epistemológica mais adequada à democracia. Conclui-se, ao final, que a mediação se constitui em prática capaz de proporcionar a emancipação das pessoas dentro da sociedade, pois garante a voluntariedade e resgata a comunicação entre os conflitantes, configurando-se como prática democrática capaz de restabelecer o equilíbrio e a paz social. A metodologia utilizada no estudo é descritiva e analítica, desenvolvida por meio de pesquisa bibliográfica.
\end{abstract}

Palavras-chave: Epistemologia do diálogo; Mediação; Resolução de conflitos; Pessoa e amizade; Hannah Arendt.

1 Doutoranda em Direito Constitucional pela Universidade de Fortaleza (Unifor). Mestre em Direito Constitucional pela Universidade de Fortaleza (UNIFOR). Juíza de Direito (CE). Jovinadavila@gmail.com.

2 Doutora em Direito Constitucional pela Universidade de Fortaleza (UNIFOR). Mestre em Direito Tributário pela Universidade Federal de Minas Gerais (UFMG). Professora de pós-graduação (Mestrado e Doutorado) em Direito Constitucional da Universidade de Fortaleza (UNIFOR). Pesquisadora do CELA. Procuradora Fiscal do Município de Fortaleza. Naterciasiqueira@yahoo.com.br. 


\begin{abstract}
The study addresses mediation as an instrument for resolving conflicts. It seeks to rethink the relationship between individuals and the form of solving their conflicts, through mediation, based on the concepts and discussions of Hannah Arendt on politics, citizenship, and friendship. In so doing, it is argued that dialogic practice is a condition for a person to have equal dignity to any other, in order to later consider that the technology of dialogue, rather than the discovery of truth, is the most adequate epistemological practice of democracy. It is concluded that mediation is a practice capable of providing the emancipation of people within society, because it guarantees volunteering and revives communication between the conflicting parties, becoming a democratic practice capable of restoring balance and social peace. The descriptive and analytical methods were used in this study, which was developed through bibliographic research.
\end{abstract}

Keywords: Conflict resolution; Epistemology of dialogue; Mediation; Person and friendship; Hannah Arendt.

Resumen: El estudio aborda la mediación como instrumento de resolución de los conflictos. Se busca repensar la relación entre los individuos y la forma de solución de sus conflictos, por medio de la mediación, con base en los conceptos y en las discusiones de Hannah Arendt sobre política, ciudadanía y amistad. Al proceder, se argumenta que la práctica dialógica es condición para que se sea persona con igual dignidad a cualquier otra, para, posteriormente, pensar la tecnología del diálogo, en vez del descubrimiento de la verdad, es la práctica epistemológica más adecuada a la democracia. Se concluye, al final, que la mediación se constituye en práctica capaz de proporcionar la emancipación de las personas dentro de la sociedad, pues garante la voluntariedad y rescata la comunicación entre los contradictorios, se configuran como práctica democrática capaz de restablecer el equilibrio y la paz social. La metodología utilizada en el estudio es descriptiva y analítica, desarrollada por medio de investigación bibliográfica.

Palabras-clave: Epistemología del diálogo; Mediación; Resolución de conflictos; Persona y amistad; Hannah Arendt.

\title{
INTRODUÇÃO
}

A mediação busca um espaço de diálogo, no qual as pessoas, de forma livre e responsável, possam escolher a melhor opção para a solução de seus conflitos, com o auxílio de uma terceira pessoa imparcial - mediador. Objetiva não somente um acordo, mas, principalmente, trabalhar os relacionamentos conflituosos de modo a despertar nas pessoas a capacidade de gerenciar suas vidas, transformar o conflito e a si próprias, além de prevenir novas disputas.

A mediação trabalha a alteridade quando um dos envolvidos no conflito se coloca no lugar do outro, a fim de compreender o seu sentimento e a sua dificuldade e, assim, ter uma visão melhor do problema que os envolve, em um 
ambiente democrático, diferente do que ocorre em um processo judicial, por exemplo, em que a decisão não é tomada pelas partes e, muitas vezes, não são abordados os aspectos emocionais do caso analisado. Dessa forma, falar em mediação é falar em autonomia, cooperação e solidariedade.

Assim, o objetivo geral detém-se na análise da eficácia da mediação como instrumento de resolução de conflitos, sob os parâmetros teóricos de Hannah Arendt. A partir de então, sistematiza-se a base axiológica que fundamenta e justifica a mediação como prática dialógica integrante da democracia e da construtiva da igualdade, que lhe é característica, de maneira a se ressaltar que a consensualidade adquire status de princípio constitucional do processo, estritamente relacionado às cláusulas pétreas.

A escolha de Hannah Arendt como marco teórico se dá pela defesa que ela realiza do diálogo e da palavra ativa, como forma indispensável à solução pacífica de conflitos. Isto porque numa prática dialógica se procede à escuta e à exposição de si e do outro, no esforço conjunto de compreensão e sistematização de perspectivas o qual permite a construção da verdade plural. O pensamento de Hannah Arendt possibilita que se analise a adequação da prática jurídica e do funcionamento das instituições sociais às demandas culturais contemporâneas, carregadas do valor da equidade e da cidadania. Mais: instiga repensar o direito em contexto epistemológico diferente do silogismo e pertinente à democracia, que investe na "construção" em vez da "descoberta".

Para tanto, o trabalho está estruturado em três partes. Inicialmente, abordase o conflito, a partir do pensamento de Hannah Arendt. Após, estuda-se a mediação como instrumento de cidadania. Já, na terceira parte, trata-se da amizade como política e da sua relação com a mediação, para no quarto tópico se analisar o contexto epistemológico que se julga mais adequado às democracias contemporâneas. Ao final, conclui-se que a consensualidade não apenas se justifica, como realiza a cidadania e as reivindicações democráticas, já que propõe a superar o conflito pela prática "ativa" dialógica e não pela conduta "paciente" da descoberta de uma "verdade" hermética, já que dotada da autoridade da vontade geral que, particularmente, não é de ninguém. 
"Un différend est um désacord sur un point de droit ou de fait, une contradiction, une opposition de thèses juridiques ou d'intéréts entre deux personnes" ${ }^{\prime \prime}$, foi como em 30 de agosto de 1924, no caso das "Concessiobns Mavrommatis Palestine", a Corte Permanente de Justiça Internacional assim definiu conflito, para fins de estabelecer a sua competência: as controvérsias poderiam ser jurídicas ou políticas, ao passo que somente as jurídicas seriam aptas de serem levadas à sua consideração ${ }^{4}$. Desnecessária que seja a problemática da competência, o conceito de conflito pela Corte elaborado revela-se interessante por já qualificá-lo como "complejidad [...] no sólo adquiere este carácter por la cantidad de elementos que intervienen [...] sino que debemos tener em cuenta que es um processo que deviene em el tempo" 5 .

A complexidade, por sua vez, verifica-se não apenas no processo do conflito, mas, igualmente, na forma de tratá-lo, ou seja, na sua terapêutica, que lhe pode fomentar consequências positivas ou negativas. O que, de tudo, não se duvida é que negar o conflito não favorece a paz, ao passo que buscar compreender os valores, os pontos de vista e o contexto dos envolvidos, assim como os vários elementos que compõem essa complexidade, ajuda a estabelecer o diálogo e facilita uma solução pacífica.

Ury, ao falar sobre os conflitos, lembra que Hannah Arendt talvez estivesse certa, quando após o fim da Primeira Guerra Mundial indicou que "o principal motivo para a persistência na guerra não é uma vontade secreta de morrer da espécie humana nem os lucros dos fabricantes de armas, mas o simples fato de que a guerra funciona como juiz supremo das divergências entre nações" ${ }^{\prime \prime}$. Diz o autor que, em qualquer litígio, seja pequeno ou grande, entre indivíduos ou grupos, pode haver a tentativa de diálogo, mas quando não se consegue um acordo, a luta funciona como juiz, embora tenha um alto preço. A coação e a 3 Rec. C.P.J.I. Concessions Mavrommatis en Palestine, arrêt du 30 août 1924, Série A n.2, p. 11.

4 GODINHO, Thiago José Zanini. A decisão do estado em recorrer a uma solução jurisdicional de suas controvérsias. Revista da Faculdade de Direito da UFMG, Belo Horizonte, n. 52, jan/jun.2008, p. 366.

5 SUARES, Marinés. Mediación en la argentina. In: BRAGA Neto, Adolfo; SALES; Lília Mais de Morais (Org,). Aspectos atuais sobre a mediação e outros métodos extra e judiciais de Resolução de conflitos. Rio de Janeiro: GZ Ed., 2012, p. 185.

6 URY, William. Chegando à paz: resolvendo conflitos em casa, no trabalho e no dia a dia. Tradução de Jussara Simões. Rio de Janeiro: Campus, 2000, p. 22. 
força são uma linguagem que pode ser compreendida por todos e, quando uma das partes perde, o conflito resta resolvido, pelo menos por um determinado momento. Assim, o que impede que a paz seja alcançada, mais do qualquer outro fator, é a falta de opção diante da coação quando o conflito se torna grave.

De acordo com Vezzulla, o conflito é estudado por distintas técnicas e ciências do conhecimento ${ }^{7}$. A estratégia militar está baseada em conflitos reais e potenciais entre os países, assim como o comércio internacional se funda nos interesses que podem produzir conflitos e estabelecer regras especiais para os vários mercados. A Sociologia e a História estudam os conflitos sociais e, para explicar a história e a evolução dos povos, muitas são as teorias que se fundamentam na existência de conflitos de classes, de raça e comerciais.

Nos escritos de Hannah Arendt, o conflito ganha especial tratamento na esfera do público. Na Promessa da Política, Arendt desenvolve a reflexão de que o convívio equânime entre indivíduos de igual relevância, mas diferentes e plurais, se dá a partir da esfera política, inicialmente ambientada na pólis ateniense. A pólis era o ambiente do público, em que todos podiam expressar sua opinião (doxa), serem vistos, ouvidos e compreendidos pelos demais. Já na família, que representava a vida privada, imperava a desigualdade, na qual esposa, filhos e serviçais não eram nem reconhecidos como humanos. Mas na pólis, assevera Arendt, todo homem tinha a sua doxa, a sua abertura para o mundo; ou seja, o modo de ver de cada indivíduo de acordo com a posição que ocupa no mundo era respeitada. O conjunto de opiniões (doxai) formaria o mundo das relações humanas - o espaço-entre.

A eclosão da esfera social, que não era nem privada e nem pública, é um acontecimento recente, que apareceu com a era moderna e tomou a forma política de Estado-nação. Não obstante o evento do "social", Arendt entende que a pólis tornou-se, na cultura ocidental, um modelo para o entendimento da constituição de um governo, para a organização política das relações humanas. Por ocasião do seu livro "A condição Humana", ela ressalta que o surgimento das cidades-estados despertou no homem a capacidade de conviver com os demais

7 VEZZULLA, Juan Carlos. Teoria prática da mediação. Curitiba: Instituto de Mediação e arbitragem do Brasil, 1998, p. 21. 
por meio da ação (práxis) e do discurso (lexis), dos quais surge o domínio dos assuntos sociais: os homens não mais estariam isolados em suas vidas privadas, já que passaram a cultivar a confiança no mundo comum.

Arendt continua a desenvolver sua teoria, ainda em "A condição humana", no sentido de que a possibilidade da política é a pluralidade como condição humana, pelo fato de os homens habitarem o mundo e viverem na terra, que compreende mais que as condições em que a vida foi dada ao homem, que o faz um ser igual aos demais, mas, ao mesmo tempo, distinto e único. Os homens vivenciam sua condição humana pelo modo de vida - vita activa, que compreende três atividades fundamentais: o trabalho, que é a atividade em si, estritamente relacionada à subsistência e que assegura a vida da espécie; a obra, que se manifesta na cristalização do produto do trabalho, a incorporar o elemento de durabilidade; e a ação, que representa o lugar do homem na política e que responde, propriamente, pelo novo e revela toda a complexidade e singularidade de ser humano.

A pluralidade humana, condição básica da ação e do discurso, tem o duplo aspecto da igualdade e da diferença. Se não fossem iguais, os homens seriam incapazes de compreender-se entre si e as gerações anteriores, ou de fazer planos para o futuro e prever as necessidades das próximas gerações. Se não fossem diferentes dos demais que existiram, existem ou virão a existir, os homens não precisariam do discurso ou da ação para se fazerem entender: "o discurso e a ação revelam essa distinção única. Por meio deles, os homens podem distinguir a si próprios, ao invés de permanecerem apenas distintos"8. A ação e o discurso se dariam, em sua maior parte, no espaço-entre ${ }^{9}$, caracterizado pela pluralidade, elementarmente paradoxal, pois é a pluralidade de seres únicos, salienta Arendt ao longo de "A condição humana".

Assim, os homens vivenciam um mundo comum, marcado pela pluralidade e relacionado à condição mais geral da existência humana: o nascimento e a morte. Com a natalidade surge a possibilidade de iniciar algo novo, de agir,

8 ARENDT, Hannah. A condição humana. Tradução de Roberto Raposo. Rio de Janeiro, Forense Universitária, 2010, p. 220.

9 ARENDT, A condição humana, p. 228. 
inclusive com o exercício da liberdade ${ }^{10}$. A ação, pela palavra ativa, relaciona-se intimamente com a liberdade justamente pela capacidade de romper com práxis tradicionais voltadas à subsistência e iniciar o novo: ação, nascimento e liberdade são elementos que caracterizam a vida no espaço público e que se realizam na prática dialógica mediante a qual a pessoa se põe e se disponibiliza à "presença" do outro.

Já na obra "Sobre a violência", Hannah Arendt analisa a natureza e as causas da violência ao tempo em que faz uma crítica à sua apologia. Em sua reflexão, distingue violência de poder, vigor, força e autoridade, por entender que são fenômenos distintos e se referem a diferentes qualidades e, se assim não fossem, não existiriam. A violência distingue-se por ter caráter instrumental, pois depende de orientação e de justificação pelo fim almejado; no entanto, nunca será legítima.

Quando fala da violência, Arendt entende que há a ruptura das relações sociais por meio da força, cuja consequência é o abandono do diálogo e da capacidade de negociação. A violência, pelo seu caráter instrumental, é também racional e deriva da relação humana que objetiva alcançar um fim a justificá-la. A violência retira do indivíduo a possibilidade de participação política. A violência "não promove causas, nem a história, nem a revolução, nem o progresso, nem o retrocesso; mas pode servir para dramatizar queixas e trazê-las a atenção pública"11.

Morton Deutsch, por sua vez, reconhece que os conflitos ocorrem entre pessoas, grupos ou nações, e que todos são influenciados por variáveis como: 1) as características das partes em conflito; 2) as relações anteriores existentes entre as partes; 3 ) a natureza do problema que originou o conflito; 4) o ambiente social em que ocorreu o conflito; 5) o público interessado no conflito; 6) as estratégias e as táticas empregadas pelas partes no conflito; e 7) as consequências do conflito para cada participante e para outras partes interessadas ${ }^{12}$.

O conflito em si não é mau e, assim como as crises, faz parte do ser humano. A forma de resolver o conflito, muitas vezes, mediante a violência, a força, é

10 ARENDT, A condição humana, p. 233.

11 ARENDT, Hannah. Sobre a violência. Tradução de André de Macedo Duarte. 2.ed. Rio de Janeiro: Civilização Brasileira, 2010, p. 99.

12 DEUTSCH, Morton. The resolution of conflict: construtive ans destructive processes. New York: New Haven and London: Yale University, 1973, p. 05-07. 
que pode ser negativa. Declara Arendt que a raiva e, às vezes, a violência que a acompanha fazem parte das "emoções 'naturais' do humano e extirpá-las não seria mais do que desumanizar e castrar o homem"13.

Conforme Ury, a ideia não é eliminar o conflito, pois este é natural e tem a capacidade de trazer mudanças ${ }^{14}$. Mais, o conflito, como decorrência das diferenças, possibilita a agregação de perspectivas cuja tendência epistemológica é a completude do objeto analisado. Está no centro do processo democrático. Antes, o ideal consiste na identificação do conflito antes que ele se intensifique. O conflito não surge do nada, normalmente origina-se de tensões latentes, desenvolve-se e "transforma-se em conflito aberto, explode em luta pelo poder e, daí, atravessa o limiar do conflito destrutivo e da violência". O objetivo é manter a trajetória de intensificação do conflito abaixo desse limiar.

Sobre o assunto, também assevera Warat, por ocasião do seu livro "O ofício do mediador", que os conflitos nunca desaparecem, podem ser transformados, pois, geralmente, tenta-se intervir sobre o conflito e não sobre o sentimento das pessoas. Ao longo dos séculos, o ser humano perdeu as necessidades do inconsciente amoroso, que foram transformadas em necessidades simbólicas, de maneira que a identificação ocorre pelas ideias e pelos pensamentos sem chegar aos sentimentos. A mente resolve quem é amado ou odiado e situa a pessoa no conflito. A mediação pode desfazer as camadas superficiais para restabelecer a integridade nos confrontos com o outro.

A prevenção da má administração dos conflitos, a busca do diálogo, a possibilidade de discussão do conflito, comportamentos, problemas, direitos e deveres para com os envolvidos e a substituição da competição pela cooperação ensinam a paz, pondera Lília Maia de Morais em seu livro "A mediação de conflitos: família, escola e comunidade". Em "A condição Humana", Arendt afirma que "a paz é um absoluto"15, mesmo que a história registre que os períodos de guerra quase sempre venham a superar os períodos de paz.

Assim, o conhecimento sobre a constituição das sociedades, a análise da violência e as formas pelas quais ocorrem, incentivam os homens a aprenderem 
maneiras mais pacíficas de solucionarem suas divergências e de buscar o emprego de meios não violentos para a resolução dos conflitos, como a mediação.

\section{A MEDIAÇÃO COMO INSTRUMENTO DA CIDADANIA}

O conflito, conforme o anteriormente salientado, é um processo complexo, de forma que não pode ser abrangido totalmente em uma definição e, talvez, não seja passível de ser trabalho por apenas um único viés, como o da força. Spengler defende a mediação como um procedimento democrático, porque "acolhe a desordem-e, por conseguinte o conflito-como possibilidade positiva de evolução social"16. A mediação busca "numa matriz autônoma, cidadã e democrática, que seja um salto qualitativo ao ultrapassar a dimensão de resolução adversária de disputas jurídicas modernas", que se assentam no litígio e na cientificidade que determina a descoberta da verdade.

As práticas sociais utilizadas pela mediação, como sustenta Spengler, representam um instrumento para a realização da cidadania, "na medida em que educam, facilitam e ajudam a produzir diferenças e realizar tomadas de decisão, sem a intervenção de terceiros que decidem pelos afetados em um conflito"17. Salienta que tratar de democracia, autonomia e cidadania tem, por um lado, o sentido de ocupar-se da capacidade de autodeterminação das pessoas em relação e com os outros. Aduz que a autonomia é uma maneira de ensejar diferenças e decidir "em relação à conflitividade que nos determina e configura em termos de identidade e cidadania". A autonomia representa "um trabalho de reconstrução simbólica dos processos conflitivos das diferenças que nos permite formar identidades culturais e nos integrarmos ao conflito com o outro, com um sentimento de pertinência comum"18.

Pois bem, o enfoque de Hannah Arendt ao tema cidadania alcança duas perspectivas, uma em sentido mais amplo e outra com fundamento na participação

16 SPENGLER, Fabiana Marion. Mediação e alteridade: a necessidade de inovações comunicativas para lidar com a atual (des)ordem conflitiva. In: LUCAS; Douglas Cesar; SPENGLER, Fabiana Marion (Org.). Justiça restaurativa e mediação: políticas públicas de tratamento dos conflitos sociais. Ljuĺ: Unijuí, 2011, p. 236.

17 SPENGLER, Fabiana Marion, Justiça restaurativa e mediação: políticas públicas de tratamento dos conflitos sociais, p. 235.

18 SPENGLER, Fabiana Marion, Justiça restaurativa e mediação: políticas públicas de tratamento dos conflitos sociais, p. 235. 
ativa dos cidadãos na pólis. O primeiro enfoque encontra-se firmado nos estudos da autora sobre a situação jurídica dos apátridas e desenvolve-se a partir da expressão "direito a ter direitos", tratada em sua obra "Origens do totalitarismo".

Ao falar da cidadania como o direito a ter direitos, Lafer, ao escrever a sua obra "A reconstrução dos direitos humanos: um diálogo com o pensamento de Hannah Arendt", compreende que, segundo Hannah, a asserção dos direitos humanos, concebido como convivência coletiva, requer um espaço público que permite a construção de um mundo comum ao qual somente se tem acesso por meio do pleno exercício da cidadania. Por isso, para Arendt, o primeiro direito humano, do qual emergem os demais, é o direito a ter direitos. Lafer, ao analisar a reflexão de Arendt, afirma que isso significa que, pelo vínculo da cidadania, se pertence a algum tipo de comunidade juridicamente organizada e é possível viver em uma estrutura na qual se é julgado por ações e opiniões, com base no princípio da legalidade. Os direitos humanos pressupõem a cidadania, não somente como meio, mas como princípio substantivo, de maneira que o ser humano, quando despojado de estatuto político, perde suas qualidades substanciais como a de ser tratado pelos demais como semelhante, em um mundo compartilhado. Então, o vínculo da cidadania mostra-se primordial para a dignidade da pessoa humana.

Em outra perspectiva, para Arendt, exercer a cidadania significa fazer parte de uma comunidade. A pluralidade humana depende da presença constante de outras pessoas que possam ver e ouvir. Agir e falar são manifestações externas do ser humano. Com palavras e atos o homem se insere no mundo, e essa inserção funciona como um segundo nascimento, no qual se confirma e se assume o aparecimento físico original. "Ser político, viver em uma pólis, significava que tudo era decidido mediante palavras e persuasão, e não força e violência"19. Com o desaparecimento das cidades-Estado, o termo vita activa perdeu a significação política e passou a expressar todo tipo de participação ativa nas coisas do mundo.

Estudar a cidadania a partir das ideias de Arendt leva à ressignificação das estruturas políticas e sociais modernas. Várias desigualdades podem ser criticamente avaliadas e valoradas. Mas dentre elas, a mais significativa consiste na privação do ser humano da cidadania, que muitas vezes se dá como sanção.

19 ARENDT, Hannah. A condição humana, p. 31. 
É o que relata Arendt, calcada na experiência do totalitarismo: a negação imperceptível da manifestação por meio da ação e do discurso corresponde à negação de acesso do ser humano ao espaço público e ao mundo. Como salienta Arendt (2012, p. 397), as pessoas não percebiam que a humanidade, concebida como uma família de nações, "havia alcançado o estágio em que a pessoa expulsa de uma dessas comunidades rigidamente organizadas e fechadas via-se expulsa de toda a família das nações" 20 .

Falar em cidadania, em qualquer época, significa referir-se às pessoas que têm opinião. Cidadão é aquele que pode ter voz, opinar e decidir por si mesmo. $\mathrm{O}$ poder de decidir foi mudando com a história, em alguns tempos relacionava-se à coisa pública, em outros, à constituição de lugares de encontros e comunicação, mas com a característica comum de construir com o "outro" o sentido de cidadania. O outro possui diferentes características, e o espaço da cidadania foi profundamente excludente. Na Antiguidade, os vínculos de cidadania eram estabelecidos entre os homens livres, excluídos os escravos. Para o século XXI, deve-se pensar em uma cidadania que compreenda as mudanças no modo de conceber e enfrentar a vida, mais humana, comprometida com os relacionamentos pessoais, não somente com a coisa pública, como adverte Warat, também em seu livro "O ofício do mediador".

A participação das pessoas como protagonistas na solução de seus conflitos pode ser alcançada por meio da mediação. De acordo com Sales, a mediação tem por objetivo "a solução e a prevenção de controvérsia, a inclusão e a paz social"21. A solução e a prevenção das controvérsias surgem pelo diálogo pacífico, com o incentivo da cooperação e da solidariedade entre as partes. A inclusão social, pelo estímulo concedido às pessoas para que participem na procura pelo entendimento, bem como quando confere aos envolvidos a responsabilidade de decisão do conflito, além de configurar acesso à Justiça. Objetiva também a paz social, quando previne a má administração dos conflitos, por entender o conflito como característica própria do ser humano, capaz de estimular o progresso das

\section{ARENDT, Hannah. Origens do totalitarismo, p. 397.}

21 SALES, Lilia Maia de Morais. A mediação de conflitos e a paz social. In: SALES, Lilia Maia de Morais (Org.). Estudos sobre mediação e arbitragem. Rio de Janeiro - São Paulo - Fortaleza: ABC, 2003, p. 132. 
Novos Estudos Jurídicos

relações, pela comunicação pacífica, além de conscientizar as pessoas de sua responsabilidade individual e social.

A mediação permite que as partes possam constituir, ao longo de seu procedimento, motivadas pelo mediador, soluções que possibilitem compatibilizar os interesses conflitantes, abordando as questões tuteladas juridicamente, bem como todas aquelas que podem influir na relação entre as partes, a fim de que possam restabelecer a comunicação e os vínculos que foram rompidos pelo conflito. Estabelecer um acordo que traga satisfação mútua é um fator de pacificação social.

O instrumento da mediação, ademais, aproxima ajustiça dos cidadãos e revelase como um dos instrumentos possíveis de realização do conceito Arendtiano de cidadania, segundo o qual cidadão é aquele que possui a capacidade de discutir e decidir seus conflitos. A mediação traz a concepção da condição humana de liberdade no meio social, pois o ser humano se identifica no mundo por meio da interação, quando deixa o isolamento e busca a comunhão com os demais.

\section{A AMIZADE COMO POLÍTICA E SUA RELAÇÃO COM A MEDIAÇÃO}

A mediação é um meio para a resolução de conflitos que "não é somente vocacionado no auxílio às pessoas envolvidas em conflitos a possuírem uma alternativa ao modelo tradicional de resolução, mas sobretudo uma opção pela escolha do método mais adequado para tanto"22. Na mediação, um terceiro imparcial, utilizando-se de habilidades e técnicas de mediação, age como facilitador ao auxiliar os litigantes a encontrarem a solução de seu desentendimento por meio da restauração do diálogo. "O mediador, como um 'regente de orquestra' deve conduzir o processo, com segurança, sensibilidade e descrição"23. A sua expertise deve ser vocacionada à promoção da compreensão mútua e à instauração da prática dialógica entre as partes, que ao se porem, reciprocamente, como pessoas aos olhos uma da outra, palmilham em conjunto à construção da resolução do conflito.

22 BRAGA NETO, Adolfo; SALES; Lília Mais de Morais. A mediação de conflitos no contexto comunitário. In: BRAGA NETO, Adolfo; SALES; Lília Mais de Morais (Org.). Aspectos atuais sobre a mediação e outros métodos extra e judiciais de resolução de conflitos. Rio de Janeiro: GZ Ed., 2012, p. 22.

23 ALDENUCCI, Lidercy Prestes. Mediação de conflitos familiares. In: BRAGA NETO, Adolfo; SALES; Lília Mais de Morais (Org.). Aspectos atuais sobre a mediação e outros métodos extra e judiciais de Resolução de conflitos. Rio de Janeiro: GZ Ed., 2012, p. 120. 
Assim, o objetivo da mediação é que as partes envolvidas possam, de forma livre e responsável, e utilizando suas próprias percepções e ideias, solucionar a controvérsia na qual estão envolvidas. Neste processo, o mediador é o facilitador, o "agente da realidade, e mantendo-se atento em suas próprias emoções evita se perder nos ilusórios e nos sonhos dos mediados e procura despertá-los para assumirem suas responsabilidades" 24 . A responsabilidade pela resolução do conflito é, entretanto, das partes envolvidas, razão pela qual a mediação é a prática, dentre as disponíveis, com maior potencial transformador, seja pela perspectiva pessoal, social e política.

Enquanto que na mediação o "mediador facilita a comunicação, sem induzir as partes ao acordo"25, na conciliação "o mediador sugere, interfere, aconselha" 26 . Já na arbitragem "as partes elegem um árbitro para solucionar as divergências [...] ao contrário da negociação e da mediação, as partes não possuem o poder de decisão, o qual se encontra a cargo do árbitro"27. A mediação, o que se torna claro na comparação entre as três metodologias expostas, é a que apresenta maior força ativa de cidadania. Ela "constitui algo mais que apenas um método para lograr acordos que terminem com as disputas, senão que também atua como uma verdadeira força transformadora [...] através da vivência de um processo desse tipo, descobrir habilidades, ser valorizado e reconhecer ao outro"28.

Na mediação, por conseguinte, exercita-se a condição intrínseca humana: colocar ao mundo a sua doxa. Nela, pratica-se a alteridade no compasso em que um dos envolvidos se coloca no lugar do outro, a fim de compreender o seu sentimento e a sua dificuldade e, assim, ter uma visão melhor do problema que os envolve. Ao referir-se à alteridade, Hannah sustenta que ela é um aspecto importante da pluralidade humana. No homem, "a alteridade que ele partilha com tudo o que existe, e a distinção, que ele partilha com tudo o que vive, tornam-se unicidade, e a pluralidade humana é a paradoxal pluralidade dos seres

24 ALDENUCCI. Aspectos atuais sobre a mediação e outros métodos extra e judiciais de resolução de conflitos, p. 120.

25 SALES, Lília Maia de Morais. Justiça e mediação de conflitos. Belo Horizonte: Del Rey, 2003, p. 38.

26 SALES, Lília Maia de Morais. Justiça e mediação de conflitos, p. 38.

27 SALES, Lília Maia de Morais. Justiça e mediação de conflitos, p. 41.

28 NORDENSTAHL, Ulf Christian Eiras. Propostas para construir um modelo de mediação penal. In: BRAGA NETO, Adolfo; SALES; Lília Mais de Morais (Org.). Aspectos atuais sobre a mediação e outros métodos extra e judiciais de resolução de conflitos. Rio de Janeiro: GZ Ed., 2012, p. 102. 
únicos"29. Já em "A promessa da política", Hannah afirma que ver o mundo pelo ponto de vista do outro é uma percepção política por excelência.

Falar em alteridade é muito mais que falar de um procedimento cooperativo, solidário e autocompositivo. Trata-se de transformar o conflito e se transformar no conflito, em face da possibilidade assistida de poder se olhar a partir do olhar do outro e, com isso, chegar à "reserva selvagem - todos os componentes afetivos ou amorosos que ignoramos em nós mesmo e a reserva selvagem" do outro - o que o outro emocionalmente ignora de si mesmo ${ }^{30}$. Sócrates, segundo Arendt, já ensinava que "somente aquele que sabe viver consigo mesmo está apto a viver ao lado dos outros" 31 .

Assim, alteridade, também entendida como outridade, representa a revalorização do outro no conflito por afetar os sentimentos, os desejos, o lado inconsciente do conflito, "em detrimento do excessivo privilégio outorgado aos moldes de dizer do direito, o litígio"32.

Existem conflitos que requerem, mais ou menos, atenção aos aspectos emocionais. Como sustentam Fischer e Shapiro, em um processo de negociação, se envolvem tanto a razão como a emoção, sendo que esta última pode tanto ser positiva como negativa. Em uma negociação em que a emoção é positiva, com referência à outra pessoa, propicia uma relação harmoniosa e de confiança, e pode aprimorar o relacionamento; enquanto as emoções negativas, como raiva e frustração, promovem aflição e relações desequilibradas. Asseveram que nenhum ser humano está livre da realidade das emoções, as quais podem arruinar ou ser um grande ativo em uma negociação, pois afetam o corpo, o raciocínio e o comportamento de todos ${ }^{33}$.

O problema de uma negociação não está, propriamente, nas posições antagônicas, mas se reflete no conflito entre necessidades, interesses e temores existentes entre os conflitantes. Os desejos e as preocupações indicam os interesses que estão "por trás da algazarra das posições. Sua posição é algo

29 ARENDT, Hannah. A condição humana, p. 220.

30 WARAT, Luis Alberto. O Ofício do mediador. Florianópolis: Habitus, 2004, p. 62.

31 ARENDT, Hannah. A promessa da política, p. 63.

32 WARAT, Luis Alberto. O Ofício do mediador, p. 62.

33 FISHER, Roger; SHAPIRO, Daniel. Além da razão: a força da emoção na solução de conflitos. Tradução de Arão Sapiro. Rio de Janeiro: Imago, 2009, p. 11-21. 
que você decidiu. Seus interesses são aquilo que fez com que você se decidisse dessa forma"34. A conciliação dos interesses e não das posições é o que torna possível elaborar uma solução, pois por trás de posições opostas, existem não só interesses conflitantes, mas, muito mais, interesses em comum.

O diálogo é a forma que o ser humano possui de expressar seus sentimentos, desejos e dilemas. Hannah, por ocasião da obra "Homens em tempos sombrios", ao falar do filósofo Jaspers, afirma que ele apreendeu o que é essencial para todo o âmbito dos assuntos humanos, a faculdade do diálogo, a precisão de ouvir, a paciência de se prolongar sobre um assunto e, principalmente, a capacidade de atrair coisas que poderiam passar em silêncio pela área do discurso, fazendo com que fossem dignas de serem comentadas. Assim, no falar e no ouvir, Jaspers consegue mudar, aprofundar e, especialmente, iluminar.

Sócrates, é como o descreve Arendt, em "A promessa da Política", fazia política por meio do diálogo. Para o filósofo, o diálogo era compartilhado pelos amigos. Conversar com os amigos torna a coisa comum, que com o transcurso do tempo e da vida adquire uma articulação específica e começa a formar um pequeno mundo que é compartilhado pela amizade. Sócrates utilizava a amizade (philia) a partir da cidadania ateniense.

Hannah destaca o elemento político da amizade, quando afirma que é no dialogo autêntico que "cada um dos amigos pode entender a verdade inerente ao outro" 35 . A amizade faz com que os amigos se tornem parceiros em um mundo comum e juntos possam construir uma comunidade, nesse sentido Hannah filia-se ao pensamento de Aristóteles de que a amizade e não a justiça, como asseverou Platão em sua obra "A República", indica "ser o laço que une as comunidades".

Assim, a amizade, na comunidade, para os clássicos é conhecida a partir do ponto de vista político, tratada como uma virtude baseada na parceria e na solidariedade que deve existir no mundo comum, mais do que por motivos pessoais. Modernamente, a amizade foi colocada no âmbito privado, da intimidade. Aristóteles, ao falar da amizade, concluiu que "o amigo é um outro eu" que significa que se pode com o amigo empreender o diálogo de 34 FISHER, Roger; PATTON, Bruce; URY, Willian. Com chegar ao sim: negociação de acordos sem concessões. Tradução de Vera Ribeiro e Ana Luíza Borges. 2. ed. Rio de Janeiro: Imago, 2005, p. 59-60.

ARENDT, Hannah. A promessa da política, p. 59. 
pensamento que se faz consigo mesmo. Por sua vez, Sócrates diria que o eu é também uma espécie de amigo, pois a experiência que é capaz de conduzir esses assuntos é a amizade e não a individualidade, uma vez que antes de conversar consigo mesmo a pessoa conversa com os outros e descobre que pode conduzir um diálogo não apenas com o outro, mas consigo mesmo ${ }^{36}$. Dessa forma, a convivência com o outro e consigo mesmo traz para o homem a reflexão de sua condição no mundo; a responsabilidade e os deveres diante dos demais e não apenas a expectativa de ser detentor de direitos.

O diálogo possibilita a reflexão que pode levar à compreensão e à empatia entre as partes, diminuindo e, quiçá, cessando a possibilidade de novos conflitos. Não se pode esquecer que a convivência humana é complexa, podendo ser permeada de hostilidades e violência, uma vez que "a comunidade não é feita de iguais, mas ao contrário, de pessoas que são diferentes e desiguais" ${ }^{37}$.

Dessa forma, como defende Spengler, em sua participação na Coletânea "Justiça restaurativa e mediação: políticas públicas de tratamento dos conflitos sociais", o diálogo deve ser transformador, ou seja, capaz de transformar uma relação entre indivíduos que se encontram em realidades antagônicas, restabelecendo a comunicação rompida ou estabelecendo a que, até então, não existia. Complementa Ury que o diálogo é exigente, necessita "coragem para enfrentar a dor das diferenças humanas e conversar de forma vulnerável sobre o que realmente importa" 38 .

A insistência no hábito do diálogo implica o investimento na responsabilidade da pessoa para se ser autenticamente e para reconhecer o outro como pessoa com igual dignidade. Nesta dinâmica, os vários elementos que compõem a complexidade, que é o litígio, são trabalhados, o que permite um seu enfrentamento total, com possibilidade de resolução total. Mais: no exercício do diálogo, vivencia-se a igualdade de forma reflexiva e intencional, e não como "valor normativo" imposto coativamente numa dinâmica de autoridade. A mediação, por conseguinte, uma vez que implica a resolução consensual dos conflitos, pode levar a transformações sociais positivas e duradoras. A mediação,

36 ARENDT, Hannah. A vida do espírito: o pensar, o querer e o julgar. Tradução de César Augusto R. de Almeida, Antônio Abranches e Helena Franco Martins. Rio de Janeiro: Civilização brasileira, 2008, p. 2011.

38 URY, Willian. Chegando à paz: resolvendo conflitos em casa, no trabalho e no dia a dia, p. 130. 
ao permitir que se trabalhem os vínculos vários pelos quais se tecem as relações entre pessoas - jurídicos, sociais e afetivos -, equilibra os diversos campos de desarmonia e alicerça a philia.

\section{PRÁTICA JURÍDICA NO CONTEXTO EPISTEMOLÓGICO DO DIÁLOGO}

Diálogo, equidade e cidadania, desde os tempos gregos, aparecem como elementos de uma sociedade política. A verdade, na pena de Sócrates, não é simplesmente descoberta, mas construída pelo diálogo entre iguais, quando o homem se põe e considera o outro como pessoa que merece igual respeito. Ou seja, o exercício dialógico, que implica ouvir com consideração e falar com autenticidade e reflexividade, permite que se avance na construção de verdades, uma vez que nele se reúnem os diversos pontos de vista elaborados a partir das diferentes perspectivas sobre o mesmo problema.

Mais do que objeto de descoberta, a verdade é construída pelo diálogo paritário, crítico, reflexivo: é preciso ver o outro pelo ponto de vista do outro, mas também ser visto pelo outro no seu próprio ponto de vista. Tal compreensão epistemológica, por sua vez, ao ser resgatada e aplicada aos tempos contemporâneos, possibilita que se repense a crença de que a norma "posta" funciona como instrumento preferencial de resolução de conflitos. Tal metodologia, é bem verdade, serviu a relevantes interesses e operou mudanças significativas na política, uma vez que atendeu aos interesses burguês e republicano de segurança e estabilidade, de cientificidade e seriedade. Ou seja: reter o direito à letra da lei, sob a dinâmica da dedução, afastava a prática jurídica do arbítrio judicial mediante metodologia que Ihe conferia aparente exatidão. Com isto, alimentava-se a crença de o direito não se encontrar à mercê dos homens, mas ao abrigo de instituições, relativamente, impessoais ${ }^{39}$.

O direito, pelo silogismo legal, se resguardava na crença da descoberta da verdade mediante investigação racional: a descoberta da norma aplicável ao caso concreto e a posterior aplicação asséptica, sem preocupação com a legitimidade. Funcionava o direito como ciência natural: prática descritiva de um evento. Até porque a verdade teria a característica atávica de ser boa e justa, o que bastaria à

39 PERELMAN, Chaïm. Lógica jurídica. Tradução de Virgínia K. Pupi. Sâo Paulo: Martins Fontes, 1999 , p. 33. 
satisfatória solução do litígio. Referida metodologia, por outro lado, se fortalecia pela crença mítica na vontade geral, que teria a aptidão para desvendar o "que" seria compartilhado pela vontade racional de todos - esta sim, incorruptível pelas inclinações e paixões egoístas e arbitrárias. A vontade geral se encontraria em um plano superior às emoções e à consciência efetivamente vivenciadas, e embora não fosse passível de ser alcançada por todos, seria pelos representantes do povo.

A verdade, a descoberta e a racionalidade eram os elementos epistemológicos adequados para a solução dos conflitos. Neste contexto, esquecia-se dos limites da lei à regulação satisfatória de casos concretos, pela sua natureza de abstração e generalização. Isto porque a lei regula pela técnica do típico, do normal, sem descer às singularidades dos casos concretos. Ocorre que em determinadas situações as singularidades são relevantes para a regulamentação, de maneira que a lei não traz uma solução satisfatória. Já por isso, Aristóteles falava de uma das dimensões da justiça particular, a da equidade, que demandava a adequação da lei às singularidades relevantes do particular.

Masnãoapenasos limites decorrentes da natureza degeneralidadeeabstração da lei, como a própria figura da vontade geral, instigam ao questionamento do protagonismo da norma "posta" como metodologia adequada de solução do litígio. A perspectiva de que a vontade geral não é acessível a todos, já que demanda descoberta por análise racional acessível a poucos, fragiliza a concepção da cidadania como participação mediante prática dialógica. O investimento na racionalidade apta à descoberta da verdade diminui a dimensão humana de agente político. Na perspectiva Arendtiana: esgarça ao homem a oportunidade e a responsabilidade de ser pessoa, tanto aos seus olhos, como aos olhos do outro, ao insistir numa epistemologia autoritária e "violenta" de resolução do conflito, que se fundamenta na hierarquia superior da verdade racional que, por sua vez, se impõe pela "força" do Estado.

Já o diálogo, como tecnologia de construção - não de descoberta -, integra a pessoa na elaboração da vontade estatal: ele permite a difusão e a capilarização da prática de cidadania, que é medida necessária para se revitalizar a democracia, em especial nesses momentos de descrédito na política representativa. Ou seja, 
em vez de concentrar a "cena política" na arena dos representantes, deve-se investir na difusão de processos dialógicos por ocasião da construção da vontade estatal, inclusive quando apresentar natureza concreta e individual. Referida metodologia fortalece a cidadania e, por via de consequência, a participação e a intencionalidade na esfera pública: possibilita que a pessoa se ponha com a palavra ativa, capaz de romper com o ciclo de repetições acríticas e criar o novo, por vezes mais adequado à cultura contemporaneamente vivida do que antigas manifestações construídas em contextos não mais existentes.

A mediação revela-se, precisamente, por um desses instrumentos de difusão da cidadania política mediante integração em uma prática dialógica, aberta para as singularidades e as "variadas" "verdades" que não, necessariamente, se excluem, mas se somam para a construção "da" "verdade". É uma técnica que rompe com a epistemologia mítica da vontade descoberta e se abre à verdade das condições particulares. A voz ativa de que fala Arendt deve ser sentida nos vários momentos da construção da vontade estatal, tanto por razões do direito a ter direitos, como porque o diálogo, mas não a descoberta, é a prática que permite que cada qual seja a si, que a sociedade seja pluralmente equânime e que os conflitos sejam efetivamente superados, posto que a metodologia de enfrentamento pela palavra ativa gera o afeto de pertencimento que é fundamental não apenas à legitimidade, mas à equidade que informa a democracia.

\section{CONSIDERAÇÕES FINAIS}

$\mathrm{Na}$ atualidade, vê-se a preocupação das pessoas na busca de formas de resolução de conflitos que possibilitem a compreensão dos valores e dos pontos de vista dos conflitantes, por meio do diálogo, de forma livre e responsável, com o objetivo de alcançar uma solução pacífica e duradoura. Nesse sentido, um dos meios de solução de conflitos não adversarial é a mediação, uma prática transformativa baseada no consenso, na cooperação, na voluntariedade e no respeito, apta a despertar a capacidade de autodeterminação das pessoas, na direção de seus problemas pessoais e daqueles surgidos como membros de uma comunidade política. 
O fenômeno da mediação, por sua vez, recepciona ressignificações relevantes à democracia quando analisado mediante os conceitos de Hannah Arendt, especialmente sobre: política como ação e pluralidade como condição da ação humana. A autora buscou entender, a partir dos filósofos gregos, o pensamento político dos ocidentais, como modernamente se apresenta. O espaço público, como evidenciou, é fundamental para o desenvolvimento da política: é o espaço em que os particulares podem expor suas diversas opiniões, um espaço de cidadania. A autora entende os indivíduos no mundo como responsáveis, pois são e não apenas estão dentro do mundo.

Conforme Arendt, as pessoas dentro do mundo, na esfera pública, colocamse como sujeitos coletivos e não como pessoas isoladas. Dessa forma, a esfera pública é um espaço de diversidade de opiniões, entendimentos, interesses e divergências, e a amizade fundamenta o diálogo e a ação que capacita os homens a chegarem ao acordo em relação aos dissensos.

Mais: o diálogo pela palavra ativa é o que torna o ser humano numa pessoa. Tal afirmação possui profundas consequências sociais, existenciais e axiológicas: implica o reconhecimento de que a dignidade humana se dá na possibilidade do diálogo, que permite que amigos se mostrem e se compreendam como pessoas. Por esta perspectiva da palavra ativa como condição de vida da pessoa chega-se ao descrédito de um ambiente epistemológico, cujo protagonismo dá-se pela descoberta racional da verdade, atavicamente boa e, portanto, ontologicamente adequada para a resolução dos conflitos.

Antes das reflexões de Arendt decorre uma epistemologia baseada na palavra ativa, na escuta atenta e reflexiva, no diálogo como hábito de convívio e superação de conflitos, o que é pressuposto para a pessoa ser pessoa. Mais do que uma filósofa política, Hannah trata de conceitos axiológicos intrínsecos à cultura pública das democracias contemporâneas, que se caracteriza pelo reconhecimento da igual dignidade de cada indivíduo; ou seja, da pessoalidade igualmente inerente a todos. A axiologia informa a epistemologia pelo conceito de uma democracia plural, que ontologicamente briga com a hierarquia. De acordo com esta ordem de consideração, a consensualidade e seus instrumentos apresentam-se em íntima conexão à democracia e à dignidade que lhe é imanente, de maneira que assume o status de princípio constitucional. 
A mediação, como técnica da consensualidade, atua como instrumento de exercício de cidadania e traz o compromisso da participação no exercício do diálogo, de maneira que se coaduna à democratização da sociedade, ao tempo em que constrói novos cidadãos, conscientes de seus direitos e deveres, tanto no domínio público como no privado. Assim, a cidadania deve ser vista na perspectiva de relação entre os cidadãos e o Estado, e também da relação entre os próprios cidadãos como coletividade, movidos por valores de solidariedade, autonomia, cooperação, autodeterminação e respeito.

\section{REFERÊNCIAS DAS FONTES CITADAS}

ALDENUCCI, Lidercy Prestes. Mediação de conflitos familiares. In: BRAGA Neto, Adolfo; SALES; Lília Mais de Morais (Org.). Aspectos atuais sobre a mediação e outros métodos extra e judiciais de Resolução de conflitos. Rio de Janeiro: GZ Ed., 2012.

ARENDT, Hannah. A condição humana. Trad. Roberto Raposo. Rio de Janeiro: Forense, 2010. ARENDT, Hannah. A promessa da política. Trad. Pedro Jorgensen Jr. 5. ed. Rio de Janeiro: Difel, 2013.

ARENDT, Hannah. A vida do espírito: o pensar, o querer, o julgar. Trad. Cesar Augusto R. de Almeida, Antônio Abranches e Helena Franco Martins. Rio de Janeiro: Civilização Brasileira, 2008.

ARENDT, Hannah. Homens em tempos sombrios. Trad. Denise Bottimann São Paulo: Companhia das Letras, 2008.

ARENDT, Hannah. Origens do totalitarismo. Trad. Roberto Raposo. São Paulo: Companhia de Bolso, 2012.

ARENDT, Hannah. Sobre a violência. Trad. André de Macedo Duarte. 2. ed. Rio de Janeiro: Civilização Brasileira, 2010.

BRAGA Neto, Adolfo; SALES; Lília Mais de Morais. A mediação de conflitos no contexto comunitário. In: BRAGA Neto, Adolfo; SALES; Lília Mais de Morais (Org,). Aspectos atuais sobre a mediação e outros métodos extra e judiciais de Resolução de conflitos. Rio de Janeiro: GZ Ed., 2012.

C.P.J.I. Affaire des concessions mavrommatis em palestine.Haia, 30 de Agosto de 1924. Disponível em: https://www.icj-cij.org/files/permanent-court-of-international-justice/ serie_A/A_02/06_Mavrommatis_en_Palestine_Arret.pdf.

DEUTSCH, Morton. The resolution of conflict: constructive and destructive processes. New York: New Haven and London: Yale University, 1973.

FISHER, Roger; SHAPIRO, Daniel. Além da razão: a força da emoção na solução de conflitos. Tradução: Arão Sapiro. Rio de Janeiro: Imago, 2009. 
FISHER, Roger; URY, William; PATTON, Bruce.Como chegar ao sim: negociação de acordos sem concessões. Tradução: Vera Ribeiro e Ana Luíza Borges. 2. ed. Rio de Janeiro: Imago, 2005.

GODINHO, Thiago José Zanini. A decisão do estado em recorrer a uma solução jurisdicional de suas controvérsias. Revista da Faculdade de Direito da UFMG, Belo Horizonte, n. 52, p. 355-384, jan/jun.2008, p. 366.

LAFER, Celso. A reconstrução dos direitos humanos: Um diálogo com o pensamento de Hannah Arendt. São Paulo: Companhia das Letras, 1988.

PERELMAN, Chaïm. Lógica jurídica. Tradução de Virgínia K. Pupi. Sâo Paulo: Martins Fontes, 1999.

SALES, Lília Maia de Morais. A mediação de conflitos: família, escola e comunidade. Florianópolis: Conceito Editorial, 2007.

SALES, Lília Maia de Morais. A mediação de conflitos e a paz social. In: SALES, Lília Maia de Morais (Org.). Estudos sobre mediação e arbitragem. Rio - São Paulo - Fortaleza: $A B C$, 2003. p.130-244

SALES, Lília Maia de Morais. Justiça e mediação de conflitos. Belo Horizonte: Del Rey, 2003.

SPENGLER, Fabiana Marion. A fraternidade como base política da mediação de conflitos.

Revista Novos Estudos Jurídicos - eletrônica, n. 1, v. 20 - jan./abr. 2015. Disponível em: <siaiap32.univali.br/seer/index.php/nej/article/download/7207/4103>. Acesso em: 10 nov. 2016.

SPENGLER, Fabiana Marion. Mediação e alteridade: a necessidade de "inovações comunicativas" para lidar com a atual (des)ordem conflitiva. In: SPENGLER, Fabiana Marion; LUCAS, Douglas Cesar (Org). Justiça restaurativa e mediação: políticas públicas de tratamento dos conflitos sociais. Ijuí: Unijuí, 2011. p. 201-241.

SUARES, Marinés. Mediación en la argentina. In: BRAGA Neto, Adolfo; SALES; Lília Mais de Morais (Org.). Aspectos atuais sobre a mediação e outros métodos extra e judiciais de Resolução de conflitos. Rio de Janeiro: GZ Ed., 2012.

URY, William.Chegando à paz: resolvendo conflitos em casa, no trabalho e no dia a dia.Trad. Jussara Simões. Rio de Janeiro: Campus, 2000.

VEZZULLA, Juan Carlos. Teoria prática da mediação. Curitiba: Instituto de Mediação e Arbitragem do Brasil, 1998.

WARAT, Luís Alberto. O ofício do mediador. Florianópolis: Habitus, 2004. 